\title{
Marginal groups in marginal times: Gypsy and Traveller parents and home education in England, UK.
}

\begin{abstract}
This article examines the experiences of home education for Gypsy and Traveller groups in England, UK. We argue that home education is perceived in a particular historical 'moment' characterised in the media and more generally throughout society by 'risk'. Against this backdrop this article considers Gypsy and Traveller experiences of home education and their relationships with local education authorities. Drawing on case study data with ten Gypsy and Traveller families living on the South coast of England we argue that the marginal status of Gypsy and Traveller families exposes them to particular vulnerabilities associated with failure, incompetence and lack of concern regarding the education of their children. This is further heightened in present day 'risk society'. Drawing on the work of Ulrich Beck, we suggest home education is both a reaction to the risks associated with modernisation and also a perceived risk in itself when equated with issues of child protection and welfare. Despite maintaining community networks and longstanding traditions of home education, Gypsy and Traveller lifestyles are still perceived as being at risk within a 'moment' in which home education is under scrutiny.
\end{abstract}

Keywords: home education, Gypsies and Travellers, risk society, Beck

\section{Introduction}

In England, as in many parts of Europe and North America, there has been a significant rise in the numbers of parents who decide to home educate their children (Webb, 2010;

Winstanley, 2013). Home education in England was brought into the public arena in May 
2008 when seven year old Khyra Ishaq was starved to death in Birmingham in the West Midlands under the care of her mother and step father. Despite repeated attempts by social workers to visit Khyra, at the time of her death she weighed only $16.8 \mathrm{~kg}$. The parents reported to school authorities that they were home educating Khyra. This tragedy led to a significant review into home education in the UK (Badman, 2009). In this article we argue that there has been a particular 'moment' in which home education has been thrust into the public arena and judged in relation to child protection issues around safety, security and wellbeing. One consequence of the moral panic surrounding the events in the West Midlands has been to characterise home education as a source of considerable risk in children's lives; particularly in relation to marginal or non-mainstream families.

As a distinct group who choose to educate their children differently, home-educators are perhaps identified as distancing themselves from the shared communal morality described by Beck (2006) as a ‘cosmopolitan vision'. Gypsies and Travellers, who have often traditionally chosen to home educate and have often been regarded as a marginalised community, could in this historical 'moment' potentially potentially become doubly distanced. This article examines how risk materialises for Gypsies and Travellers who choose to home educate and considers the educational consequences of such risks.

The United Nations Convention on the Rights of the Child (UNCRC) gives children and young people over 40 substantive rights including the right to express their views freely, the right to be heard in legal or administrative matters that affect them and the right to seek, receive and impart information and ideas. Article 12 makes clear the responsibility of signatories to give children a voice. 'Parties shall assure to the child who is capable of forming his or her own views the right to express those views freely in all matters affecting 
the child, the views of the child being given due weight in accordance with the age and maturity of the child' (1990:5). However, Badman states, 'under the current legislation and guidance, local authorities have no right of access to the child to determine or ascertain such views’ (2009: 5). Badman's report, The Review of Elective Home Education in England, makes 18 recommendations to ensure good practice for home educating. Many of these focus on the role of local authorities and the rights of the child in decision making processes regarding home education. They include a compulsory national registration scheme (locally administered) for all children who are of statutory school age, who are or become electively home educated. This would enable local authorities to have knowledge of and provide support for those being home educated. Badman calls for a change in the current legal and statutory obligations to monitor the efficiency and suitability of home education. He recommends that local authority officers have 'the right of access to the home and the right to speak with each child alone if deemed appropriate or, if a child is particularly vulnerable or has particular communication needs, in the company of a trusted person who is not the home educator or the parent/carer' (2009: 40).

In April 2010, Ed Balls, then Education Secretary in the Labour Government, responding to concerns about the Khyra Ishaq case proposed a number of controversial clauses in the Education Bill. These included a requirement for home educators to register their children with the local authority; and, for the local authority to implement compulsory annual visits to home educating families. This led to home educators demonstrating outside parliament and these clauses were eventually dropped in a concession made to pass the Education Bill before parliament dissolved ahead of the general election. As shadow Chancellor of the Exchequer he has continued to strongly urge the coalition government to re-introduce the legislation on home education as ‘an urgent priority’ (The Guardian, May 2011). 
In this article we examine the experiences of home education for Gypsies and Travellers, a non-mainstream group, living in England. We argue that the perception of home education in a particular historical 'moment' characterised by the tragic death of a child is directly associated to the perception of marginal groups in society, by the media and by education authorities. This article looks particularly at the educational experiences of Gypsies and Travellers against the backdrop of this media interest. Gypsy and Travellers’ marginal status exposes them to particular vulnerabilities, including the identification of 'risk' associated with their perceived failures, incompetence and lack of concern about their children’s education. Beck argues that in a 'risk society', 'Risk may be defined as a systematic way of dealing with hazards and insecurities and introduced by modernisation itself'. (1992: 21 original emphasis). In one sense, home education is a reaction to modernisation in 'risk society'; it is a means of adapting to perceived failures in state schooling. In this sense, 'the wealthy (in income, power and education) can purchase safety and freedom from risk’ (Beck, 1992: 35 original emphasis). Ironically however, home education itself has also become understood as a risk when associated with issues of child protection and welfare; specifically when these are identified as issues of concern about marginal groups. This article considers how such differential discourses surrounding risk contribute to and strengthen educational inequalities.

\section{Gypsies and Travellers in England, UK}

There has been considerable debate about the appropriate nomenclature for people from nomadic or semi-nomadic backgrounds with terms such as 'Gypsy' being used both selfascriptively and as a term of abuse. 'Gypsy/Roma’ and ‘Travellers of Irish Heritage’ are defined as racial groups under the Race Relations (Amendment) Act (2000) as legitimate minority ethnic communities; and, since 2003/04, ‘Gypsy/Roma’ and 'Travellers of Irish 
Heritage' have been included as distinct ethnic categories within school census data. ${ }^{1}$ In this article the terms 'Gypsy and Traveller' are used, as these were the terms that respondents used to define themselves.

Gypsy and Traveller children’s lack of attendance at school has been well-documented (Swann, 1985; Author B ref, 2012). However, since the late 1960’s there have been dramatic increases in the numbers of children attending schools (authors ref, 2009). Most recently, research has shown that families perceive changes in their work and commercial prospects may require children to learn new skills. Many parents identified the necessary skills in areas such as information technology which they believe could be better delivered by schools (author ref 2010). The relationship between Gypsy and Traveller groups and schools needs to be understood in terms of their longstanding adaptability to economic conditions in order to generate income (Levinson and Sparkes, 2006). There is a noticeable trend amongst Gypsy and Traveller families to send their children to primary school but not necessarily make the transition to secondary school or stop attending at an early age (author ref 2010).

With the onset of adolescence, many Gypsy and Traveller children are on the one hand expected to be treated as adults and yet on the other their parents remain exceptionally protective about the impact of exposure to permissive non-Gypsy culture, (such as taking drugs and alcohol and being sexually active from an early age). Schools are invariably identified as sites in which Gypsy and Traveller pupils are routinely bullied and subjected to racism by other pupils and staff (D’arcy, 2014; Author’s ref, 2010; Cemlyn et al, 2009). The conjunction of poor schooling experiences and fears of cultural erosion are at the root of high absenteeism from schools by Gypsy and Traveller pupils (Levinson, 2007). In addition

\footnotetext{
${ }^{1}$ These groups were originally included in the PLASC (Pupil Level Annual School Census) data (DfE, 2010).
} 
Gypsy and Travellers have traditionally often followed the gender-centric roles of their parents. Traditionally sons may leave school at an early age but will go to work and learn the tools of economic independence from their fathers, whilst girls will help their mothers with domestic chores (Cemlyn et al, 2009).

\section{Home Education}

There are considerable variations across Europe and North America in the legislative and regulatory policies relating to home education. In Europe some countries accommodate those who home educate (Belgium, Denmark, France, UK), in others it is legal under restrictive conditions (Austria) and in some it is illegal (Spain, Greece, Germany) (Steininger, 2010). Until 1980, home schooling ${ }^{2}$ was illegal in the USA and it is only since 1993 that it has been legalised in 50 states (Cooper and Sureau, 2007; Gaither, 2009). Home schooling is legal in Canada, where parents are required to register their child with the local school or school board and comply with their province’s relevant Education Act (Aurini and Davies, 2005). Although Canadian home schoolers remain fully responsible for their children's education they are often able to enrol them in classes or activities provided by public or private institutions.

In the USA there are differences between how states choose to regulate home educators. In some states parents have to register children with their education authority, comply with compulsory attendance laws and follow a curriculum approved by the state. Additionally there may be requirements for home educators to be teachers, families to be subject to regular

\footnotetext{
${ }^{2}$ We recognise the diversity of terms used to describe the process by which children are educated at home. The term 'home schooling' is commonly used in the US and Canadian literature.
} 
visits from education officials, or for parents to send test scores to their education authority. In some states however, parents are not required to follow any of these regulations.

As in the UK, concerns have been raised in the USA about home schooling. Stewart and Neeley (2005) argue that home schooling remains under-reported and is difficult to monitor for a number of reasons including: families choosing not to register their children; families switching between private, public and home schooling; and, parents registering as part-time home schoolers. Lubienski (2000) suggests that, 'The elevation of individual choice epitomised by home schooling ... has considerable implications for democracy and the common good' (2000: 208). He argues that the pattern of private and individual decisions involved in home schooling undermine parental responsibility to the education of the community and the common good.

\subsection{Home Education in the UK}

In the UK, parents are responsible for providing their children with an education under Section 7 of the Education Act 1944 (England and Wales). The Act states that parents of children of compulsory school age should ensure they receive an efficient full-time education which is suitable to their age, ability and aptitude and to any special educational needs they may have. The terminology used in the Education Act 1944 (later replaced by the 1996 Act) was challenged by an appeal case at Worcester Crown Court in $1981^{3}$. The judge defined a suitable education as one which prepares the child for life in modern civilised society and

\footnotetext{
${ }^{3}$ Harrison and Harrison vs. Stevenson.
} 
enables the child to achieve their full potential. Article 2 of Protocol 1 of the European Convention on Human Rights states that,

No person shall be denied the right to education. In the exercise of any functions which it assumes in relation to education and to teaching, the State shall respect the right of parents to ensure such education and teaching is in conformity with their own religious and philosophical convictions (2009:8).

Parents have a right to educate their children at home. ${ }^{4}$ There are many reasons why parents choose to educate their children at home; these may include dissatisfaction with schooling, bullying, cultural or religious reasons or if their child has special educational needs (D’Arcy, 2014; DfE, 2013; Hopwood et al, 2007; Webb, 2010; Winstanley, 2013). Parents are not required to register or seek approval from their local authority to educate their children at home. Furthermore, local authorities have no statutory duties in relation to monitoring the quality of home education. However, under Section 437 (1) of the Education Act 1996 parents must satisfy the local authority that they are providing their child with a 'suitable education'. ${ }^{5}$ Local authorities can intervene if they believe that parents are not providing a ‘suitable education'. If this is the case, the local authority can issue a school attendance order (Section 437 (3)). Local authorities also have a duty under section 175 (1) of the Education Act 2002 to safeguard and promote the welfare of children. Section 175 (1) does not

\footnotetext{
${ }^{4}$ It should be noted that elective home education is different to flexi-schooling whereby children are registered with a school and attend school on a part-time basis. They spend other parts of the week being educated at home by parents. This arrangement is between the head teacher, rather than the local authority to negotiate with parents. Children being educated within this arrangement are in the same position as any registered pupil and so attract full funding for the school.

${ }^{5}$ Defining a 'suitable education' can be problematic and is a contentious issue for those who decide to home educate (McIntyre-Bhatty, 2007).
} 
however, give local authorities the power to enter the homes of children who are being educated at home for the purposes of monitoring provision of elective home education. ${ }^{6}$

There are no national guidelines on elective home education; each local education authority has their own individual guidelines. In England, the DfE (2013) recommends that each local authority should have a written policy statement on elective home education and be willing to provide guidance for parents who request it. Parents who decide to educate their children at home do not have to teach their children the national curriculum or have set hours when they teach them. Furthermore, parents are not required to have any level of education or qualifications to teach their children at home (DfE, 2013). Education Otherwise state, 'Parents are not legally required to give the LEA access to their home or their child. Article 8 of the Human Rights Act 1998 requires respect for the privacy of home and family life, and it should be remembered that where parents choose not to allow access this does not of itself constitute a ground for concern about the education being provided’ (2005: 10).

Recent research by Badman (2009) suggests that many home educators do have access to support and guidance from home educating organisations on recognising and dealing with child protection issues and many emphasise the importance of informal networks and their links with their local communities. However this is not the case for all children, Webb (2010) identified many home educated children who were not registered with their local authority and may not have any links to support networks. Our own research suggests that many Gypsy and Traveller parents see home education as the best option for their children enabling them to receive an education that is suitable to their needs and more useful for them

\footnotetext{
${ }^{6}$ The Children Act (2004) provides the legislative framework for developing children's services as detailed in the Every Child Matters agenda.
} 
in later life than that offered by formal schooling. However some Gypsy and Traveller parents, (and it should be noted some non-Gypsy parents), may be opting for home education to avoid prosecution and to avoid contact with 'official' type organisations such as schools, Education Welfare Officers and in some cases the Traveller Education Service (see author ref, 2009).

It is difficult to estimate the numbers of children who are being home educated as parents do not have to register their child with the local authority. Research has reported that around 20,000 children are registered with local authorities as being home educated but according to Badman (2009) this is an underestimate and the figure could be as high as 80,000. However, Badman (2009) provides no evidence to support this claim or an explanation of how these figures are calculated. McIntyre-Bhatty (2007) has argued that concerns about home education include surveillance arrangements, children’s welfare and their potential educational achievements. A body of research has shown that home-educated children do not underachieve and are not at any greater 'risk' than schooled children (D'Arcy, 2014; Monk, 2004; Rothermel, 2002). Research also suggests that decisions to home educate are not taken lightly and are usually taken after consultation with the children involved (Arora, 2006). McIntyre-Bhatty (2007) emphasises that home educated children are not 'vulnerable' but on the contrary, parents have a greater investment in their children’s intellectual, psychological and social development and that increased government regulation regarding home education may not necessarily make any difference to children's attainment.

\section{Methodology}

Ten case studies were conducted with Gypsy and Traveller families living on the South Coast of England (UK). In eight interviews one parent (the mother) was interviewed and in the 
other two interviews both parents participated. Families were accessed initially via the Ethnic Minority and Traveller Achievement Service ${ }^{7}$. All but one of the interviews was digitally recorded (with the agreement of respondents) and the data transcribed. In the other interview detailed handwritten notes were taken. Interview data was analysed thematically and categorised under topics and headings by generating themes and codes from which to explore meanings (Charmaz, 2006). We also conducted five interviews with educational practitioners, all of which were digitally recorded.

The aims of the research were to examine the reasons why parents decide to home educate their children; to explore the role of support agencies within EHE and to examine recent policy initiatives in EHE. The research was motivated firstly by concerns raised within a local education authority that Gypsy and Traveller families were using the terminology ‘elective home education’ as a means to avoid prosecution for school non-attendance. Secondly, the research was designed to identify the range of home education being delivered to Gypsy and Traveller children. The project therefore focussed on the practical aspects of home education, (e.g. what was being taught, by whom and what support was available to families); and also, on attitudes towards home education and education more generally.

Before the interviews were conducted, respondents were informed about the main aims and details of the research. They were assured of anonymity and confidentiality and it was agreed that the only individuals who would have access to the interviews would be the research

\footnotetext{
${ }^{7}$ The Ethnic Minority and Traveller Achievement is part of Children's Services within the County Council in which the research took place. Their service supports schools and families across the County in raising ethnic minority achievement, through bilingual assistance, projects, training, family learning and advisory support. An example of their service includes schools being offered bilingual assistance with newly arrived pupils for whom English is an Additional Language (EAL). The Service works with other children's agencies, for example Children's Centres, Extended Services, Locality Teams and Services for Young Children, to raise achievement of EAL learners and ethnic minority pupils and to promote parental involvement.
} 
team. Respondents were also told they could withdraw from the interview at any time and without explanation. They were informed that their responses may be reported in publications and reports but that their individual identities would be protected; respondent's anonymity and confidentiality would not be compromised. We filled in a research ethics form as well as an ethical protocol that was submitted to the Ethics Committee at the University where the research took place. Once ethical clearance was granted, the interviews were conducted. We were however conscious of the difficulties and dilemmas of conducting research with marginalised communities; such as the use of appropriate methodologies, differential power issues in the research process and the analysis and dissemination of data. We used our previous experiences to inform this process, (for a detailed discussion of these issues see author ref 2009).

\section{Findings}

\subsection{Reasons for choosing home education}

Talking to many parents about why they chose to educate their children at home it became clear that in many respects they were not describing a new phenomenon of 'elective home education', but rather a continuing set of traditional practices surrounding the upbringing of their children. The nomenclature of 'elective home education' reflected the current terminology of education authorities and possibly other parents, (i.e. who were not Gypsies or Travellers), rather than the terminology that respondents would generally use. The Jones ${ }^{8}$ family explained how their two teenaged boys had both attended primary school but had not made the transition to secondary school. Mr and Mrs Jones explained that upon leaving primary school the two boys worked with their father. Mr Jones outlined in detail the learning

\footnotetext{
${ }^{8}$ All family and site names are pseudonyms.
} 
outcomes he was passing on to his children; he fitted double-glazing and he had taught his children how to generate business and how to install double-glazing. When asked if he had any concerns about his children's future he very clearly stated his pride in their abilities,

'No, no worries at all - reckon they’ll be able to support themselves. Keep a family together. No problems.'

The family had minimal contact with the education authority since their youngest son, Jake, had left school. They described other elements of learning including a small amount of home tutoring for Jake, (because he showed greater interest in more academic subjects). Largely however, learning was equated with acquiring the skills necessary to generate income. In this particular case, home education was related to ensuring the successful continuity of the family business and lifestyle. This was highlighted by Mrs Jones' response to being asked why they chose home education, It’s just what we do.

When asked to explain in greater detail her views on home education, she repeated the same explanation. Within this family's history, the mother had attended primary school for several years but had very limited experience of secondary education and the father could not recall any formal schooling. In addition, both parents believed their own parents had not attended school. They were not aware of a growing wider interest in home education and in many respects, the experiences they described distanced themselves from the whole process of sedentary education; they were simply going about their way of life as they saw fit. Mrs Jones expressed this as, 
We just do what we have to do to get by - and that is it. We want our kids to read and write, but they have to learn a trade as well - so both the boys they're going to have families to look after soon. We just do what we have to.

This type of experience was typical of families who were relatively financially successful and whose income derived from their own business enterprise. Such families described practices they felt to be traditional and mirrored their own and their parents' experiences and decisions. In some respects such families seemed distanced from official or more widely understood accounts of 'elective home education'. The Jones family for example expressed no interest or awareness of locally organised support groups for home educating families. They also expressed disinterest in the need to 'tick a box' for the local authority by making a claim to being 'elective home educators', simply reiterating the traditional and effective nature of the education their family provided. In some respects it was quite striking how distanced the Jones were from media and local authority discourses about home education; their relaxed attitude counter-intuitively, seemed to highlight the wider concerns about the issue.

In discussions with another very successful family, the Smiths, whose teenaged daughter Shannon had left school at the age of 13, a slightly different picture emerged. Mr and Mrs Smith suggested that they would have liked Shannon to continue her education but that the pressures associated with exposure to permissive adolescent non-Gypsy culture, (e.g. sexual behaviour, alcohol and drug consumption), made this impossible. Withdrawing Shannon from school, Mr Smith made arrangements for her to be privately tutored and to study towards her General Certificate of Secondary Education exams ${ }^{9}$. Mr Smith explained that it

\footnotetext{
${ }^{9}$ The General Certificate of Secondary Education is a compulsory exam taken by pupils, usually at age 16 in England, UK.
} 
was important his daughter was able to support herself financially in the future and furthermore, that it was necessary to 'have qualifications these days even to get a shop assistant job’. Unlike the Jones family, Mr Smith explained the significance of 'elective home education' as a 'box to tick'. He went on to explain that Gypsies and Travellers always liked to discuss opportunities and potential strategies (in relation to anything from commercial projects to holiday ideas), and that in such discussions it 'went round like wild-fire' that ‘elective home education’ was a means of getting the education authorities 'off your back'. Mr Smith clearly understood both the rules and the local policy enforcement of home educating:

We know if we don’t send them [our children] to school, they'll [the education welfare officers] be on our backs. We can say to them that we're home educating, and everyone’s happy. A lot of the parents round here are doing it [home educating] now. Now I'm interested in education so we take her [Shannon] to the tutor twice a week. But that's me. Not everyone's that interested.

Whilst the Smith’s dissatisfaction with schooling for their teenaged daughter reflected traditional fears and concerns about secondary schools, it was interesting to note their distinctly non-traditional approach. Both the encouragement and interest in a continuing school-type education (through tutors) and the desire for their daughter to be self-reliant and independent in the future contradicted many traditional gender roles. Mr Smith, unlike other respondents, demonstrated a greater awareness of wider media discussions about home education and of the need to work both with and around the local education authorities. Unlike the Jones family he identified far more clearly a shift in the public awareness of home education and he openly developed strategies to ensure his daughter received the education 
he wanted in a manner acceptable to his family. That this was a less traditional type of education seemed linked to his perception that economies and income-generating opportunities were changing for Gypsies and Travellers. He was clearly positioning his family to be successful in the future rather than relying on their current skills. Ironically despite his very non-traditional approach, Mr Smith constantly underlined the importance to him of 'Gypsyishness' and of traditional Gypsy values in his family life, (as was reflected in his decision to withdraw Shannon from school and exposure to non-Gypsy culture).

Whilst more successful families often adopted home education, (either in traditional or nontraditional forms), to prepare their children for the future, this did not appear to be the case for children from less affluent or successful families such as those who were reliant on state benefits. These families often did not appear to be equipping their children with sets of skills that would ensure their future security but were still choosing to home educate. On the local authority Dockyard Site several mothers explained why they had withdrawn their children from school and were now home educating, (within these particular interviews the researcher noted a degree of carefully rehearsed answers between the different parents, and noted that this reflected a communal sense of grievance). The parents described problems of bullying and racist name calling in the local schools. They also claimed that Gypsy and Traveller children were classified as 'spastics, ${ }^{10}$ by the local secondary school, with all children from the site included in a Special Educational Needs class regardless of their ability. (When asked for clarification about this, parents explained that their children, children with clinical mental disorders and children with serious behavioural problems were routinely educated together outside of the usual classrooms.) Teachers at the schools were unfriendly towards Gypsies and Travellers and quick to exclude them. Finally, there was a considerable grievance with a

10 'Spastic' is a derogatory term used to describe those who have special needs and/or those with disabilities. 
previous Traveller Education Service member (TES) ${ }^{11}$, which had resulted in a physical fight between him and a mother on the site. Whilst at the time of these interviews there was probably greater tension than usual between families on the site and the local school, with the exception of the fight with the TES member, (in almost all other research the TES maintain very good relations with families, see Cemlyn et al, 2009), the concerns being expressed by parents were fairly normal. The families said they were aware that other people used home education as a means to get the authorities 'off their backs' but that in their case they wanted an education to be provided for their children by the state. However, their proposal that Gypsy and Traveller children should be educated separately was not one that was accepted by the local authority. In other interviews with individual parents, the issue of safety was raised as the main reason for withdrawing children from school.

\subsection{Type of home education Gypsy and Traveller children were receiving}

The quality, quantity and scope of home education varied tremendously. As already discussed an emphasis on non-academic learning was often a reason for choosing to home educate. There was a distinct impression that families with successful business interests often delivered very successful learning outcomes. The Jacksons owned stables and were engaged in all aspects of horse-trading. Their eldest son Tommy had left school aged thirteen to work with his father and was very talented at handling horses. Now aged 18 Tommy and his father were negotiating apprenticeship arrangements with a local farrier. His younger fifteen-yearold sister Sarah, had recently been withdrawn from school following a bullying incident. Prior to this particular incident, relations with the school had been very poor. Sarah had been

\footnotetext{
${ }^{11}$ The Traveller Education Service was introduced in the 1970s to provide support for nomadic families in terms of educational achievement and attendance. Under the Coalition government in England, funding for this serviced has been drastically cut.
} 
involved in an argument with a teacher who claimed Gypsies had not been victims of the Nazi holocaust, a dispute that escalated between the Jacksons and the school. Mr and Mrs Jackson felt that an academic education was very important for their daughter's future but that the school situation had become unbearable. They were in the process of making arrangements for a home tutor to continue their daughter's education and discussing options for taking exams with the TES. However, they also explained that Sarah was very capable of supporting herself; she was heavily involved in the family business, particularly running a lucrative side project selling Christmas trees and at weekends, she worked in a large department store where she had been promised a full-time job at the age of eighteen. For Sarah and Tommy it was apparent that provision would be made for their education in ways that accounted both for their personal and cultural needs. Within the family, the processes of learning were well established and valued and what was particularly borne out within the Jackson family was that these processes were in hand whether or not their children were in full-time education.

We know our kids will be able to look after themselves, they are being educated, but they are being educated in a different way to what you know (original emphasis).

Other families were unable to offer similar learning opportunities to the Jacksons. When asked what sort of education her son was receiving one mother (Mrs Brown) immediately responded,

Nothing. He’s not being educated. 
Despite backtracking a little on this immediate statement by suggesting that her son went fishing and watched some television, it was apparent that no structured education was provided by Mrs Brown or other family members. The Browns lived on a site where most of the families, including the Browns, were unemployed and consequently there was little scope to learn the skills associated with a trade or income generation. When questioned about what opportunities Mrs Brown would like her son to have and how he could support himself in the future she explained how they had tried to enrol him on a number of vocational, workorientated courses. However, all of these had fallen through for one reason or another; whilst some of the reasons seemed a little specious, (a potential training programme in fencing had been rejected because it was the wrong type of fencing), by and large the problems related to transport issues. The site, like many Gypsy and Traveller sites, was situated on a marginal piece of land with poor bus services available at a considerable distance from the site. There were no local amenities and the site was surrounded by 3 metre high fencing and located on land almost wholly used for heavy industry. For the Browns such isolation was compounded by not having access to a car. The family’s poverty, their inability to deliver education and the issue of isolation resulted in a poor and minimal home education for their children. Mrs Brown commented:

You can see it's hard for us, look at this [the site]. It would be better if they [the children] did get a proper education, if we had a tutor here for all the kids but we can’t pay for it ourselves. We need help to do that. We have no money to pay for it [the tuition].

Whilst it would be wrong to suggest that families were either providing a wide-ranging, successful education or alternatively were failing to deliver any education, it often appeared 
there was a disproportionate weighting at each end of this spectrum. Those families who were somewhere in between tended to aspire to delivering better quality education, often citing lack of financial resources as the main barrier to delivering an effective education. The capability to deliver home education seemed almost entirely dependant on the relative affluence of families generally linked to the success of their livelihood or business skills, rather than other factors including whether a family aspired to a traditional or non-traditional education. Financially successful families were often in a position to pass on vocational skills and afford to pay for home tutors. Children from very poor families often received no practical education and were not enrolled with home tutors, despite being officially recorded as 'electively home educated'.

\subsection{Support for home education}

Currently there is no officially sanctioned support for parents who choose to home educate. In some cases Gypsy and Traveller families benefit from the wide-ranging support of TESs. On a number of occasions it was apparent that the TES were actively assisting families who were home educating, for example by distributing books and course materials to families. During an interview with the Tanners, a family living on a small local authority site, a TES member visited the family. The family’s thirteen-year-old daughter, Julie, had been withdrawn from school over concerns about the suitability of the education being provided. The TES member came to speak to Julie and pass on a school dictionary and other books, she also discussed Julie's reading and made suggestions about useful websites she could access. Mrs Tanner and the TES member both described how important it was for Julie to continue with her education. Mrs Tanner explained that she was unable to read or write herself, making it difficult to guide her daughter, though other family members often helped. Mrs Tanner was very complimentary about the TES who had also resolved a different problem 
relating to two of her younger children attending primary school. Whilst this sort of approach by TES members is common it is not universal, and some TES members reported that they felt financially pressured not to continue working with families who chose to home educate as officially no funding was available to provide support for home educated children. Mrs Petrie, a senior manager in one local authority who had responsibility for elective home education noted:

It does appear very unfair the lack of support we make available to home educators but it does reflect very real financial constraints. We do fund home tutors but only to a very limited extent. If I fund a tutor for home educated children that means - as a direct consequence - I will not be able to fund a tutor for another child who is unable to attend school because he has cancer. That where I make the choice.

The only other support for children's education aside from the TES and other family members was from home tutors employed directly by parents. Whilst parents reported that many home tutors were very good they also noted that they were very expensive. For families on low incomes the costs were often too great, in which case they were unable to use home tutors or were only able to afford 1 or 2 hours a week. All parents suggested more support would be helpful, in particular, parents wanted more time from private tutors. Those who were paying for tutors already felt they would benefit from having greater contact time, which they currently could not afford. Other parents who were not using home tutors often stated that their first option to improve the provision of home education would be to have a home tutor. Mrs Brown suggested a tutor could visit her local authority site and teach all the children; 
We know a lot of families who have a home tutor, but that's expensive and we can't afford it. We need more help, the schools should help us and give us books or they should let a tutor come to the site so that we can use them. We can't educate them ourselves; they need to have someone who knows what they're talking about and whose job it is to do it.

Other sources of support for education were resources such as television and access to the internet. None of the families we interviewed, including a much wider cohort of pupils who were attending schools and not just those being educated at home, talked about using local libraries or museums or similar facilities. When discussing home education in particular, none of the families had made contact with various local support groups set up and used by other home educators. As Mrs Kendall said:

I've not heard of them [local home education support group]. To be honest I don't know if I would use them. I'd have to find out more about the sort of people there.

The local home education support groups were run by non-Gypsy or Traveller parents often using local libraries as a meeting space. Gypsy and Traveller families did not tend to identify such groups as encompassing their needs; if anything, their reasons for adopting home education often included the desire to create a distance between themselves and non-Gypsies and Travellers.

\section{Discussion and Conclusions: Marginal Groups in Marginal Times}

This research has highlighted the heightened interest and moral panic around 'home education' following the death of Khyra Ishaq, a child who was both being home educated 
and identified as being 'at risk'. In the wake of that tragedy there has been increased concern about child protection issues and the 'right of the child' to be home educated. These debates have been characterised by understandings of 'risk' in twenty-first century Britain.

Beck describes how a risk society has led to a process of individualisation in which, 'as a consequence people have lost their traditional support networks and have had to rely on themselves and their own individual (labour market) fate with its entire attendant risks, opportunities, and contradictions' (1992: 92). As a result of this process of individualisation, Beck argues that individuals become separated from their traditional support networks (such as family and neighbours). Beck’s description of risk society highlights a society increasingly marked by insecurity (both emotionally and financially), uncertainty, fragility and risk. Although the lives of Gypsies and Travellers often appear vulnerable to the fears generated by such insecurity, the distinct nature of Gypsy and Traveller culture does not map neatly on to understandings of such risk and strategies for its management. Gypsies and Travellers have always been situated in marginal spaces; quite literally in terms of their accommodation, but also in their engagement with state provided services such as education or healthcare and in terms of their positioning within British society. Gypsy and Traveller’s desires to retain traditional patterns of life would suggest as a community they may be less troubled by problems associated with individualisation and the erosion of community and family networks. Their marginality and difference however appear to be perceived as a marker that Gypsies and Travellers are a group identifiably at risk. At a time when more families choose to home educate and this becomes identified as the source or materialisation of greater risk it is ironic to consider that Gypsies and Travellers in many cases are not changing or adopting new approaches to their children's education. The decision-making of such families to choose to home educate reflects a continuation of very traditional practices. 
Our research suggests that Gypsies and Travellers want to hold on to their understandings of community. Often this was linked to a continuing perception of the risks posed by schooling to Gypsy and Traveller culture and way of life. A regularly repeated sentiment from many families was that schooling was, 'good for them (Gypsy and Traveller young people) but not so good for us (the wider Gypsy and Traveller community)’. Schools were associated with cultural erosion and specific risks associated with racism, bullying and discrimination; in consequence families had adopted traditional, normative behaviours such as non-attendance. Non-traditional responses to education, (such as a greater interest in mainstream education), were indicative of a changing moment in Gypsy and Traveller lives, reflecting changes to their wider economies. For some Gypsies and Travellers this reflected their individual, nontraditional approaches to education; the Smith's for example specifically cited their daughter's future security as the reason for providing an education that looked beyond traditional gender roles. For families who were unable to provide effective home education there was a sense of desperation; families on the Dockyard Site all reflected on the lack of opportunity for their children and also on the difficulties and harshness of their current lives. Within the heavily gated and fenced compound of Dockyard Site, families discussed their hopelessness in twenty-first century Britain.

The identification of 'elective home educators' who on the one hand might represent families concerned by the 'risk' of schools failing to deliver satisfactory education, or on the other hand families who because of their marginal status or personal inadequacy put their children at risk, both fail to do justice to the breadth of Gypsy and Traveller experiences. In the risk society, Beck argues that education becomes ever more important because, 'the educated person incorporates reflexive knowledge of the conditions and prospects of modernity, and in 
this way becomes an agent of reflexive modernisation' (1992: 93). Consequently, inequalities become redefined, 'in terms of an individualisation of social risks. The result is that social problems are increasingly perceived in terms of psychological dispositions: as personal inadequacies, guilt feelings anxieties, conflicts and neuroses' (1992: 100 original emphasis) and 'Social crises appear as individual crises, which are no longer (or are only very indirectly) perceived in terms of their rootedness in the social realm’ (1992: 100).

Describing a 'cosmopolitan vision', Beck (2006) suggests that a consequence of globalisation is the agglomeration of populations within a single community sharing a similar sense of morality. The world has become cosmopolitan and as a result, 'it demands a new outlook, from which we can grasp the social and political realities in which we live and act. Thus the cosmopolitan outlook is both the presupposition and the result of a conceptual configuration of our modes of perception' (2006: 3). Beck argues that in this new cosmopolitan world, 'cultural ties, loyalties and identities have expanded beyond national borders and systems of control' (2006: 7). Beck suggests new boundaries exist in which the separation of individuals has become more transparent. There is a longing for the 're-establishment of the old boundary lines’ (2006: 8). From this perspective Gypsy and Traveller groups are a group who are 'othered' both because of their longstanding positioning in society, (evidenced in media and political discourse), and also, in the current political environment identified as 'home educators', a category of people potentially deviating from standard or expected behaviours. This deviation from normal behaviour is identified as something 'new' because of the wider interest in home education, despite Gypsy and Travellers longstanding adoption of such behaviours. Within Beck's 'cosmopolitan vision', some groups who home educate are demonised, particularly during 'moments' of tragedy and crisis when confusion arises around who is considered 'fit' to home educate and who is not. This 'moment' is characterised by 
specific fears relating to a high profile tragedy being mapped onto more generic concerns and ‘commonly held beliefs’ that inform public opinion. Gypsy and Traveller parents continued desire to educate their children at home in 'the Gypsy way' demonstrates an adherence to ideals and community at odds with a 'cosmopolitan vision'. Elective home education is identified within a particular 'moment' of fear and tragedy, however, groups such as Gypsies and Travellers who in some respects have always home educated, continue to do so. Because of this they are further marginalised due to the identification of risk associated with elective home education in public discourses. As a result Gypsies and Travellers are able to manage such risk by adhering to traditional educational patterns. However, it is precisely this which enhances their marginality and continues to position them as outsiders in the risk society.

In times of crisis, in which risk and insecurities are heightened, many vulnerabilities are exposed, including those of groups such as Gypsies and Travellers, who choose to home educate and find themselves open to public interest and scrutiny. Ironically the interest in 'risk' that emerges may in itself be a factor that results in a less effective education being delivered to Gypsy and Traveller families. At a time when many families identify the need for education to be delivered from outside their community there is a growing sense that communities are less likely to engage with the school system. Or, that families will recognise the dangers posed by a heightened interest in home education of marginal groups and expend greater energy on circumventing education authorities’ perceived intrusions into their lives, rather than ensuring an effective education for their young people. 


\section{References}

Arora, T. (2006) Elective home education and special educational needs. Journal of Research in Special Educational Needs, 6 (1) 55-66.

Aurini, J and Davies, S (2005) Choice without markets: home schooling in the context of private education. British Journal of Sociology of Education, 26 (4) 461-474.

Badman, G. (2009) Review of Elective Home Education in England, a report to the Secretary of State. (London, The Stationery Office).

Beck, U. (1992) Risk Society (London, Sage).

Beck, U. (2006) Cosmopolitan Vision (Cambridge, Polity).

Charmaz, K. (2006) Constructing Grounded Theory (London, Sage).

Cemlyn, S., Greenfields, M., Burnett, S., Matthews, Z. and Whitwell, C. (2009) Inequalities Experienced by Gypsy and Traveller Communities. (Manchester, EHRC).

Children Act. (2004) (London, HMSO).

D’Arcy, K (2014) Travellers and Home education: safe spaces and inequality (London, Trentham/IOE Press).

DfE (2010) Improving the outcomes for Gypsy and Traveller Pupils (London, DfE).

DfE (2013) Elective Home Education: Guidelines for Local Authorities (London, DfE).

Education Otherwise (2005) Available from:

http://www.educationotherwise.net/index.php?option=com_content\&view=article\&id=155:c onsultations-2005\&catid=261:activities-and-consultations\&Itemid=220 [accessed January 2014].

European Convention of Human Rights (2009). (Paris, EU) 
Gabb, S. (2004) Home-schooling: A British perspective, University of Buckingham; Available from URL: http://www.seangabb.co.uk/academic/homeschooling.htm [accessed January 2014].

Gaither, M (2009) 'Home schooling in the USA: past, present and future', Theory and Research in Education, 7 (3), 331-346.

Guardian 31 May (2011) Do we need another inquiry into Home schooling?

Hopwood, V., O’Neill, L., Castro, G., Hodgson, B. (2007) The prevalence of Home

Education in England: A Feasibility Study (York Consulting LTD, Nottingham, Department for Education and Skills).

Levinson, M.P. and Sparkes, A.C. (2006) Conflicting value systems: Gypsy females and the home-school interface. Research Papers in Education, 21 (1) 79-97.

Lubienski, C. (2000) Whither the Common Good? A Critique of Home Schooling Peabody Journal of Education 75 (2) 207:232.

McIntyre-Bhatty, K. (2007) Interventions and interrogations: An analysis of recent policy imperatives and their rationales in the case of home education. Education, Knowledge, \& Economy, 1, 241-259.

Monk, D. (2004) Problematising home-education: challenging 'parental rights' and 'socialism'. Legal Studies 24(4), 568-598.

Myers, M. (2012) Gypsies, schools and education in Maitles, H and Cowan, P (eds) The challenges of teaching controversial issues in the classroom (London, Continuum).

O’Hanlon, C. and Holmes, P. (2004) The Education of Gypsy and Traveller Children (Stoke on Trent, Trentham).

Race Relations (Amendment) Act (2000). London: HMSO.

Ray, B (2006) Home schooling as educational neglect or neglected research standards? Home School Researcher 17 (1), 9-12.

Rothermel, P. (2002) Home education: aims, practices and outcomes. University of Leeds: Doctoral Thesis.

Steininger, M (2010) Where home schooling is illegal. BBC World Service, Europe Today.

Stewart, K and Neeley, R (2005) The impact of home schooling on educational enrolments in the USA. Education, 126 (2), 353-343.

UNCRC. (2009) United Nations Convention on the Rights of the Child. Geneva.

Webb, S. (2010) Elective Home Education in the UK (Stoke on Trent, Trentham). 
Winstanley, C. (2013) Too cool for school? Gifted Children and Home schooling. Theory and Research in Education. 7 (3) 347-362. 